\title{
Rodzaje i charakterystyka standardowych wkładów koronowo-korzeniowych — przegląd piśmiennictwa
}

\author{
Classification and the properties of standard \\ crown-root posts - literature review
}

Katedra i Klinika Protetyki Stomatologicznej, Uniwersytet Medyczny im. Karola Marcinkowskiego w Poznaniu

DOI: http://dx.doi.org/10.20883/df.2018.27

\begin{abstract}
STRESZCZENIE
Standardowe wkłady koronowo-korzeniowe stanowią alternatywę dla wkładów indywidualnych podczas odbudowy zębów po leczeniu endodontycznym. Bazując na dostępnym piśmiennictwie przedstawiono podział wraz z ogólną charakterystyką standardowych wkładów koronowo-korzeniowych oraz omówiono czynniki wpływające na trwałość odbudowy z ich wykorzystaniem. Porównano także właściwości cementów lutujących stosowanych do osadzania standardowych wkładów koronowo-korzeniowych. Wkłady standardowe zastosowane zgodnie z ich przeznaczeniem nie tylko upraszczają procedurę odbudowy, ale i gwarantują jej trwałość.
\end{abstract}

Słowa kluczowe: standardowe wkłady koronowo-korzeniowe, odbudowa protetyczna, odbudowa po leczeniu endodontycznym, cementy lutujące.

\section{ABSTRACT}

Standard crown-root posts are an alternative to individual posts during restoration after endodontic treatment. Basing on the available literature, in the article were presented classification together with the general characteristics of standard crown-root posts and the factors influencing the durability of the reconstruction with their use. The properties of luting cements used for infixing standard crown-root posts in root canals were also compared.

Standard posts used according to their intended purpose not only simplify the reconstruction procedure, but also guarantee its durability.

Keywords: standard crown-root posts, prosthetic restoration, post-endodontic restoration, luting cements.

\begin{abstract}
Wstęp
Wybór rodzaju trwałej odbudowy korony zęba po leczeniu endodontycznym powinien uwzględniać jej funkcjonalne i estetyczne wymagania. W przypadku znacznej utraty tkanek twardych zrębu korony konieczne jest wytworzenie retencji poprzez zastosowanie wkładu koronowo-korzeniowego standardowego lub indywidualnego. Podczas doboru wkładu należy mieć na uwadze jego długość, właściwe dopasowanie do średnicy kanału, a także dążyć do zachowania jak największej ilości zębiny i efektu obręczy (ferrule effect) [1-3]. Poniższy przegląd piśmiennictwa koncentruje się na rodzajach wkładów standardowych, ich właściwościach i wskazaniach do zastosowania, ze szczególnym uwzględnieniem czynników wpływających na trwałość odbudowy zębów po leczeniu endodontycznym.
\end{abstract}

Zastosowanie wkładów standardowych zgodnie $z$ ich przeznaczeniem $w$ przypadku znacznej utraty tkanek, jednak z zachowaniem struktury zęba powyżej brzegu dziąsłowego, upraszcza procedurę odbudowy zęba poprzez eliminację etapu laboratoryjnego, nieodłącznego w przypadku wyboru odbudowy z zastosowaniem wkładów indywidualnych [4]. Należy mieć jednak na uwadze, że wkłady standardowe, w przeciwieństwie do indywidualnych, cechuje mniejsze dopasowanie do ścian kanału, a tym samym mniejsza szczelność i odporność na złamania [5]. Uwzględniając fakt, że nie wzmacniają one struktury korzenia zęba, a służą wytworzeniu retencji dla osadzanej na nich korony protetycznej, istotny jest właściwy dobór rodzaju wkładu do danej sytuacji klinicznej [6]. Rozmiar wkładu powinien jak najdokładniej odpowiadać średnicy kanału, a kształt 
części korzeniowej w miarę możliwości jak najlepiej korespondować z jego naturalnym zarysem. Obecność cienkiej warstwy cementu na dowierzchołkowym szczycie wkładu polepsza to dopasowanie i chroni przed tzw. efektem klina (wedge effect) [7].

\section{Podział i ogólna charakterystyka wkładów standardowych}

Standardowe wkłady koronowo-korzeniowe występują w różnych długościach części korzeniowej (od 8 do $16 \mathrm{~mm}$ ) i części koronowej (od 2 do $7 \mathrm{~mm}$ ) oraz w różnych średnicach (od 0,8 do 1,9 mm). Możemy je podzielić przyjmując kryterium materiału, z jakiego zostały wykonane (Tabela 1). Pośród nich wyróżniamy wkłady metalowe: wykonane z tytanu oraz jego stopów, wkłady ze stopów złota, stopów chromoniklowych, ze stali nierdzewnej, a także niemetalowe: kompozytowe wzmacniane włóknami szklanymi, wzmacniane włóknami węglowymi, wkłady na bazie włókien polietyleno- wych (woven fiber posts, PFR), ceramiki na bazie tlenku cyrkonu [8]. Prefabrykowane ćwieki metalowe, niezależnie od tego, z jakiego materiału zostały wykonane, mogą specjalnie być dedykowane odbudowie zębów w przednim lub tylnym odcinku łuku zębowego lub mieć uniwersalne zastosowanie. Różnią się od siebie kształtem i powierzchnią części kotwiącej w kanale. Wyróżniamy wkłady stożkowe gładkościenne, stożkowe karbowane, stożkowe gwintowane, równoległe gładkościenne, równoległe karbowane, równoległe gwintowane [9]. Wkłady o karbowanej powierzchni korzeniowej, niewchodzącej w bezpośrednią interakcję ze ścianą kanału, nazywane są wkładami pasywnymi. Z kolei wkłady posiadające gwint samonacinający ścianę kanału określane są jako aktywne. Zastosowanie tych ostatnich powinno być ograniczone do zębów o krótkich korzeniach, ponieważ gwintowanie wkładu, choć wzmacnia znacznie jego retencję, wywołuje naprężenia, mogące prowadzić do złamania korzenia [5].

Tabela 1. Standardowe wkłady koronowo-korzeniowe

Table 1. Standard crown root ports

\begin{tabular}{|c|c|c|}
\hline & Rodzaj & Właściwości \\
\hline \multirow{3}{*}{ 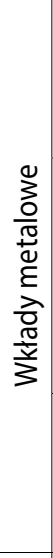 } & $\begin{array}{l}\text { - tytanowe } \\
\text { - ze stopów tytanu z glinem, } \\
\text { wanadem lub niobem } \\
\text { - ze stali nierdzewnej (Para-Post) }\end{array}$ & $\begin{array}{l}\text { - biokompatybilność } \\
\text { - wysoki moduł elastyczności } \\
\text { - bardzo dobra retencja } \\
\text { - słaba estetyka }\end{array}$ \\
\hline & $\begin{array}{l}\text { - stopy metali szlachetnych (np. } \\
\text { platyna ze złotem, pallad ze } \\
\text { srebrem, platyna ze złotem } \\
\text { i irydem) } \\
\end{array}$ & $\begin{array}{l}\text { - biozgodność } \\
\text { - nie wywołują reakcji galwanicznych } \\
\text { - wytrzymałość } \\
\text { - brak podatności na korozję } \\
\text { - nieestetyczne } \\
\text { - wysoka cena }\end{array}$ \\
\hline & $\begin{array}{l}\text { - stopy chromowo-kobaltowe } \\
\text { - stopy niklowo-chromowe } \\
\text { - pozłacane }\end{array}$ & $\begin{array}{l}\text { - dobra retencja } \\
\text { - słaba biozgodność } \\
\text { - nieestetyczne } \\
\text { - podatność na korozję — przebarwienia }\end{array}$ \\
\hline \multirow{3}{*}{ 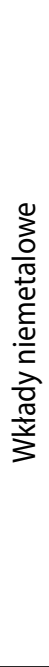 } & $\begin{array}{l}\text { - wkłady kompozytowe } \\
\text { wzmacniane włóknem } \\
\text { szklanym (FRC) }\end{array}$ & $\begin{array}{l}\text { - estetyka } \\
\text { - wymagają cementowania adhezyjnego } \\
\text { - moduł elastyczności zbliżony do zębiny } \\
\text { - łatwe do usunięcia z kanału } \\
\text { - przezierność na rtg }\end{array}$ \\
\hline & $\begin{array}{l}\text { - wkłady kompozytowe } \\
\text { wzmacniane włóknem } \\
\text { węglowym (C-Post) }\end{array}$ & $\begin{array}{l}\text { - nie ulegają korozji } \\
\text { - moduł elastyczności zbliżony do zębiny } \\
\text { - nieestetyczne } \\
\text { - gorsze właściwości mechaniczne niż wkładów metalowych }\end{array}$ \\
\hline & $\begin{array}{l}\text { - wkłady ceramiczne na bazie } \\
\text { dwutlenku cyrkonu } \\
\text { - wkłady ceramiczne } \\
\text { z dodatkiem tlenku glinu }\end{array}$ & $\begin{array}{l}\text { - biozgodne } \\
\text { - estetyka } \\
\text { - nie ulegają korozji } \\
\text { - cementowanie adhezyjne lub tradycyjne } \\
\text { - wysoka twardość } \\
\text { - trudne do usunięcia z kanału } \\
\text { - wysoka cena } \\
\text { - brak absorpcji naprężeń }\end{array}$ \\
\hline
\end{tabular}




\section{Porównanie właściwości wkładów standardowych w kontekście trwałości odbudowy $z$ ich zastosowaniem}

Najczęstszą przyczyną utraty zębów po leczeniu endodontycznym odbudowanych za pomocą wkładów standardowych są złamania zęba $(49,1 \%)$ oraz utrata retencji wkładu $(31,7 \%)$ [10, 11]. W 1020\% obserwuje się złamania pionowe korzenia, kwalifikujące ząb do ekstrakcji. Dla porównania w zębach żywych, nieleczonych kanałowo, odsetek złamań pionowych wynosi jedynie 2-5\% [12]. Odporność na złamania uzależniona jest od takich czynników jak rodzaj odbudowywanego zęba, a tym samym ilość i jakość pozostałych tkanek twardych, jego ustawienie w łuku zębowym, wielkość obciążenia okluzyjnego, a także od właściwości zastosowanego wkładu [6]. Przeprowadzone przez Gbadebo 6-miesięczne obserwacje in vivo wykazały brak statystycznej różnicy pomiędzy wytrzymałością na złamania zębów odbudowanych z zastosowaniem prefabrykowanych wkładów metalowych oraz standardowych wkładów wzmacnianych włóknem szklanym (odpowiednio 100\% i 97,5\%). Jednak już 5-letnie obserwacje Schmittera dowodzą, że przetrwanie zębów odbudowanych wkładami kompozytowymi kształtuje się na poziomie 78\% i jedynie 50\% dla zębów z wkładami standardowymi metalowymi [11]. Ellner porównując prefabrykowane wkłady złote i tytanowe zauważa, że nie ma statystycznej różnicy w trwałości odbudowy z ich zastosowaniem i po 10 latach obserwacji współczynnik uszkodzeń zębów wynosił jedynie 6\% [11]. Część badań dowodzi, że złamaniom zębów, zwłaszcza trzonowych, odbudowanych na wkładach standardowych przeciwdziała przestrzeganie zasady obręczy powyżej $2 \mathrm{~mm}$ i wówczas mniejsze znaczenie ma rodzaj i długość zastosowanego wkładu [10]. Trwałość takiej odbudowy można zwiększyć dodatkowo przez użycie do zacementowania wkładu cementu adhezyjnego [10]. Jak podaje Valea przeciętny czas funkcjonowania prefabrykowanych wkładów tytanowych Unimetric (Dentsply Sirona) osadzonych na cement Panavia F wynosi 9,6 lat [13]. Krótszy jest w przypadku zębów o wąskich kanałach i wysokości obręczy poniżej 2 mm, najdłuższy w przypadku trzonowców i górnych przedtrzonowców.

Dla jak najlepszej adaptacji wkładu standardowego, bez względu na to, z jakiego materiału jest wykonany, istotna jest właściwa preparacja kanału przy użyciu wiertła o średnicy dedykowanej danemu wkładowi. Brak dopasowania wkładu, zwłaszcza u wylotu kanału, skutkuje zbyt dużą przestrzenią dla cementu, co w przypadku stoso- wania cementów adhezyjnych może prowadzić do nadmiernego skurczu polimeryzacyjnego i debondingu [14]. Wkłady tytanowe z odbudowanym materiałem kompozytowym zrębem wykazują najlepszą odporność na złamania w testach [15]. Równie wysoką odporność wykazują wkłady cyrkonowe i ze względów estetycznych preferowane powinny być zdaniem niektórych autorów w zębach siecznych. Najmniej wytrzymałe w testach in vitro okazują się wkłady kompozytowe wzmacniane włóknem szklanym [15]. Z kolei stopy metali szlachetnych np. stop platynowo-złoto-palladowy cechują odpowiednie właściwości mechaniczne, w tym zdolność do absorpcji naprężeń, biozgodność i niepodatność na korozję, jednak podobnie do innych wkładów na bazie stopów metali odznaczają się słabymi właściwościami estetycznymi i dodatkowo wysoką ceną [16].

Mimo wysokiego odsetka klinicznych sukcesów, wkłady metalowe oraz wzmacniane włóknem węglowym są ze względów estetycznych rzadziej preferowane w przednim odcinku szczęki na korzyść wkładów na bazie tlenku cyrkonu lub kompozytowych wzmacnianych włóknem szklanym [15]. Wkłady wykonane z ceramiki na bazie tlenku cyrkonu (94,9\% $\mathrm{ZrO}_{2}$ ) wykazują biokompatybilność, odporność na korozję, możliwość natychmiastowego obciążenia, a ich retencję zwiększa się poprzez zastosowanie cementowania adhezyjnego. Są to wkłady pasywne, o kształcie równoległym w 2/3 górnej i stożkowym w 1/3 przywierzchołokowej części wkładu. Twardość wkładu ceramicznego określana w skali Vickersa wynosi 400 VHN, a to z kolei powoduje, że piaskowanie modyfikuje powierzchnię wkładu w sposób nieznaczny i nie wpływa w ich przypadku na siłę wiązania. Siła użyta w doświadczeniach in vitro do odcementowania wkładu ceramicznego w przypadku zastosowania Variolink II wynosi 228,1N ( $\pm 36,8)$, dla porównania przy zastosowaniu cementu glass-jonomerowego Fuji I to jedynie $121,8 \mathrm{~N}( \pm 17,4)$ [17]. Dodatkowo siłę wiązania w ich przypadku polepsza zastosowanie primeru (zirconia primer) opartego na fosforoorganicznych/karboksylowych kwaśnych monomerach (Z-Prime Plus) [18, 19].

Najdłużej w użyciu klinicznym spośród wkładów standardowych niemetalowych pozostają wkłady kompozytowe wzmacniane włóknem węglowym (np. wkłady C-Post, zawierające włókna węglowe zatopione w żywicy epoksydowej). Są biozgodne i nie ulegają korozji [16]. Ich wadą może okazać się mniejsza wytrzymałość mechaniczna w porównaniu z wkładami metalowymi oraz elastyczność, która przy braku zachowania obręczy 
z zębiny prowadzić może do mikroprzemieszczeń i w rezultacie odcementowania wkładu. Ponadto są przepuszczalne dla promieni rtg i wymagają stosowania widocznych na rtg cementów lutujących [19].

Ryzyko naprężeń prowadzących do złamań korzenia zęba zmniejsza się, jeżeli moduł elastyczności zastosowanego wkładu jest jak najbardziej zbliżony do modułu elastyczności zębiny [6]. Wkłady wykonane z kompozytu wzmacnianego włóknem szklanym, kwarcowym lub węglowym wykazują właściwości fizyczne porównywalne z zębiną. Dostępne wkłady FRC cechuje moduł Younga na poziomie 16-40 GPa, stopy złota $95 \mathrm{GPa}$, stopy $\mathrm{Cr}$-Co 200 GPA, dla porównania moduł Younga dla zębiny wynosi 18,6 GPa [20]. Wkłady kompozytowe wzmacniane włóknem szklanym (FRC) reprezentowane są przez kilka dostępnych na rynku produktów, w tym Glassix (Harald Nordin), Snow post (Carbotech), Parapost fiber white (Coltene/Whaledent), Luscent anchor (Dentatus), Fiber kor (Jeneric/Pentron), FRC postec (Ivoclar/Vivadent) [1]. Wkłady kwarcowe zaliczane są do wkładów estetycznych i wykonane są w całości z włókien kwarcowych, tak jak w przypadku Esthetic plus posts, Light post (RTD) lub zaprojektowane tak, że włókna kwarcowe zebrane w podłużne pęczki pokrywają rdzeń na bazie włókien węglowych (Esthetic post — RTD) [1]. Niektóre randomizowane badania in vivo również pokazują, iż wkłady wzmacniane włóknem węglowym lub szklanym gwarantują bardziej wytrzymałą odbudowę niż wkłady na bazie stopów metali pod warunkiem zachowania zębiny powyżej brzegu dziąsła [21].

Wkłady tytanowe posiadają względnie lepsze właściwości mechaniczne niż wkłady wzmacniane włóknem szklanym [22]. Wielkość naprężeń przebiegających poprzecznie do osi głównej kanału, a tym samym wzrost ryzyka złamania korzenia idą w ich przypadku w parze ze wzrostem długości zastosowanego wkładu. Nieznacznie można je zredukować poprzez wzrost średnicy wkładu, jednak wiąże się to $z$ większym opracowaniem ścian kanału, a co za tym idzie gorzej rokującym osłabieniem wartości samego korzenia [23]. Dodatkowo naprężenia wewnątrz kanału podczas cementowania wkładów metalowych gwintowanych mogą osiągnąć $1,5 \times 10(4) \mathrm{KN} / \mathrm{m}^{2}$ [24].

Doświadczenia in vitro wykazują, że najwyższa odporność na złamania cechuje zęby odbudowane wkładami FRC o średniej długości $8 \mathrm{~mm}$, umieszczonymi w kanale na $2 / 3$ długości korzenia, przy pozostawieniu przy wierzchołku 3-6 $\mathrm{mm}$ materiału, którym kanał został wypełniony podczas lecze- nia endodontycznego. Im dłuższy wkład i większy ubytek zębiny korzeniowej, tym wyższe ryzyko złamania korzenia manifestujące się najczęściej pionowym pęknięciem korzenia [25]. Wkłady krótkie częściej ulegają odcementowaniu, a ewentualne złamania powstają w okolicy przyszyjkowej $[5,20]$.

Jak pokazują badania, wkłady metalowe stożkowe koncentrują siły w okolicy wierzchołka korzenia, $z$ kolei niemetalowe w przyszyjkowej oraz środkowej części korzenia [2, 26]. Najlepsze wydają się być wkłady cylindryczno-stożkowe, gdyż zapewniają wystarczającą retencję, przy minimalnie inwazyjnym opracowaniu przywierzchołkowej części kanału [5]. Chociaż 2-letnie obserwacje Zhou i Monticelli dowodzą, że kształt wkładu cylindryczny lub zwężający się nie ma statystycznego znaczenia dla trwałości odbudowy protetycznej zęba, a występujące pojedyncze uszkodzenia mogą dotyczyć zarówno złamania korzenia, jak i odcementowania wkładu [11]. W przypadku zastosowania standardowego wkładu w kanale o owalnym kształcie znaczenie dla trwałości odbudowy ma rodzaj i grubość warstwy zastosowanego cementu [27].

\section{Cementy służące do osadzania wkładów standardowych}

Rodzaj użytego cementu mocującego wkład w kanale, a zwłaszcza jego moduł elastyczności ma szczególne znaczenie w odniesieniu do wkładów pasywnych [28]. W przypadku wkładów metalowych zalecane są cementy szkło-jonomerowe, odznaczające się adhezją do tkanek twardych zęba i działaniem kariostatycznym (ich wadą może być wrażliwość na wilgoć w pierwszej fazie wiązania) lub cynkowo-fosforanowe - łatwe w zastosowaniu i o dużej wytrzymałości na ściskanie (ich wadę stanowi duży stopień rozpuszczalności oraz brak adhezji do tkanek zęba) [16]. Cementy glass-jonomerowe wykazują lepsze właściwości wiskoelastyczne niż cementy na bazie żywic, a cechująca je higroskopijna ekspansja w drugiej fazie wiązania sprawia, że połączenie cement-zębina jest bardziej stabilne. Dodatkowo można je wzmocnić poprzez wcześniejsze kondycjonowanie zębiny EDTA przez 1 minutę w celu usunięcia warstwy mazistej [29]. Wkłady wykonane ze stali nierdzewnej cementowane są najczęściej przy użyciu cementów glass-jonomerowego bądź karboksylowego. Wadą tego ostatniego jest jednak krótki czas pracy, duża rozpuszczalność i mała wytrzymałość na ściskanie [16]. Cementy oparte na żywicach preferowane są podczas cementowania wkładów kompozytowych wzmacnianych włóknem węglowym lub szklanym oraz wkładów ceramicznych. Ich zaletę sta- 
nowi adhezja do tkanek zęba i nierozpuszczalność w płynach jamy ustnej. Do wad zaliczyć można różnorodność metod aplikacji w zależności od producenta, nadmierną grubość warstwy i wynikającą stąd podatność na mikroprzeciek [16]. Należy przy tym pamiętać o konieczności odpowiednio szerokiego opracowania kanału w celu usunięcia resztek ćwieków gutaperkowych oraz uszczelniacza, który może ograniczać siłę wiązania cementu do ścian kanału [30, 31]. Pęcherzyki powietrza, które mogą wytworzyć się podczas aplikacji do kanału cementu mogą zmniejszyć siłę połączenia z zębiną i doprowadzić do kumulacji naprężeń skutkujących odcementowaniem wkładu [32, 33]. Mikroprzeciek może ulec zmniejszeniu poprzez zastosowanie cementu adhezyjnego, wymagającego wcześniejszego zastosowania wytrawiacza w postaci $37 \%$ kwasu fosforowego. Okazuje się, że takie rozwiązanie jest korzystniejsze, niż zastosowanie systemów samowytrawiających [30]. Należy podkreślić, że bez względu na rodzaj użytego cementu, badania pokazują, że użycie zbyt grubej warstwy cementu ma negatywny wpływ na siłę wiązania do kanału [34].

Wkłady standardowe po zacementowaniu wymagają odbudowy zrębu koronowego. Najczęściej stosowanym jest materiał kompozytowy lub glass-jonomer. Niewątpliwą zaletą materiału kompozytowego jest odpowiednia wytrzymałość i estetyka, dlatego preferowane są odbudowy zrębu z jego zastosowaniem [16].

\section{Podsumowanie}

Wkłady standardowe metalowe oferują interesującą alternatywę dla odlewanych wkładów indy widualnie. Mimo że jest to rozwiązanie tańsze i znacznie przyspieszające odbudowę zęba po leczeniu endodontycznym należy pamiętać, że przy niewłaściwej selekcji przypadków klinicznych może okazać się mniej wytrzymałym rozwiązaniem, niegwarantującym retencji porównywanej z wkładami lanymi. Ponadto niewłaściwy dobór wkładu standardowego może generować naprężenia przyczyniające się do pęknięć i złamań korzenia kwalifikujące ząb do ekstrakcji. Wkłady kompozytowe na bazie włókna szklanego redukują znacznie ten ostatni problem. Jednak ich wybór w przypadku zbyt małej ilości tkanek zęba w strefie naddziąsłowej i przy nieprzestrzeganiu procedur cementowania adhezyjnego sprzyja szybkiemu ich odcementowaniu. Sukces podczas leczenia z zastosowaniem wkładów standardowych jest wieloczynnikowy i opiera się w dużej mierze na właściwej interpretacji wyjściowej sytuacji klinicznej oraz właściwościach dostępnych na rynku wkładów i wskazań do ich użycia.

\section{Oświadczenia}

Oświadczenie dotyczące konfliktu interesów Autorzy deklarują brak konfliktu interesów w autorstwie oraz publikacji pracy.

\section{Źródła finansowania}

Autorzy deklarują brak źródeł finansowania.

\section{Piśmiennictwo}

[1] Shetty N. Types of post and core systems. Journal of Oral Health. 2016;8(12):1136-1139.

[2] Upadhyaya V, Bhagava A, Parkash H, Chittaranjan $B$, Kumar V. A finite element study of teeth restored with post and core: Effect of design, material, and ferrule. Dent Res J. 2016;13:233-238.

[3] Stricker EJ, Gohring TN. Influence of different posts and cores on marginal adaptation, fracture resistance, and fracture mode of composite resin crowns on humanmandibula premolars. An in vitro study. Journal of Dentistry. 2005;34:326-335.

[4] Majewski SW. Rekonstrukcja zębów uzupełnieniami stałymi, Wydawnictwo Fundacji Rozwoju Protetyki, Kraków; 2005. s. 101-105.

[5] Karońska K. Wpływ uszczelniaczy kanałowych oraz cementów adhezyjnych na siłę połączenia wkładów z włókna szklanego z zębiną. Rozprawa doktorska, Poznań, 2015, 18-25.

[6] Scotti N, Rota R, Scansetti M, Paolino DS, Chandussi G, Pasqualini D, Berutti E. Influence of adhesive techniques on fracture resistance of endodontically treated premolars with various residual wall thicknesses. The Journal of Prosthetic Dentistry. 2013;110(5):376-381.

[7] Angerame D, De Biasi M, Cattaruzza M, Franco V, Turco G, Filingeri J, Zarone F, Sorrentino R. Resistance of endotically treated roots restored with different fibre post systems with or without post space preparation: in vitroanalysis and SEM investigation. Giornale Italiano di Endodonzia. 2016;30:111-119.

[8] Berekally T. Contemporary Perspectives on post-core systems. Austrlian Endodontic Journal. 2003;29(3):120-127.

[9] Schilinburg HT, Kessler JC. Restoration of the endodontically treated tooth, Quinteeence Publishing, Chicago;1982:127-128.

[10] Toksavul S, Toman M, Uyulgan B, Schmage P, Nergiz I. Effect of luting agents and reconstructon techniques on the fracture resistance of pre-fabricated post systems. Journal of Oral Rehabilitation. 2005;32:433-440.

[11] Marchionatti AME, Wandscher VF, Rippe MP, Kaizer OB, Valandro LF. Clinical performance and failure modes of pulpless teeth restored with posts: a systematic review. Braz. Oral Res. 2017;31(64):1-4.

[12] Jakobson SJM, Westphalen VPD, Silva Neto UX, Fariniuk LF, Schroeder AG.D. Carneiro E. The influence of metallic posts in the detection of vertical root fractures using different imaging examinations. http:// dmfr.birjournals.org.

[13] Valea MC, de la Pena V. A. Ttanium posts and bonded amalgam core longevity. The Journal of the American Dental Association (JADA). 2017;148(2):75-80. 
[14] Celik K, Belli S. The effect of different restoration techniques on fracture strength of teeth with flared roots. Journal of Adhesion Science and Technology. 2015;29(1):12-23.

[15] Toksavul S, Toman M, Uyulgan B, Schmage P, Nergiz I. Effect of luting agents and reconstructon techniques on the fracture resistance of pre-fabricated post systems. Journal of Oral Rehabilitation. 2005;32:433-440.

[16] Śpikowska-Szostak J, Dąbrowa T. Nowoczesne systemy prefabrykowanych wkładów koronowo-korzeniowych w praktyce stomatologicznej - przegląd piśmiennictwa. Dent. Med. Probl. 2009;46(4):494500.

[17] Marchan S, Coldero L, Whiting R, Barclay S. In Vitro Evaluation of the Retention of Zirconia-Based Ceramic Posts Luted with Glass lonomer and Resin Cements, Braz Dent J. 2005;16(3):213-217.

[18] Ardakani MT, Giti R, Taghva M, Javanmardi S. Effect of a zirconia primer on the push-out bond strength of zirconia ceramic posts to root canal dentin. J Prosthet Dent. 2015;114:398-402.

[19] Berekally T. Contemporary Perspectives on post-core systems. Austrlian Endodontic Journal. 2003;29(3):120-127.

[20] Góra K, Kochanowski M, Dejak B. Wpływ długości wkładów korowo-korzeniowych wzmocnionych włóknem szklanym na odporność zębów na złamania - badanie in-vitro. Protet. Stomatol. 2013;LXIII(2):127-133

[21] Baba NZ, Golden G, Goodacre CJ. Nonmetallic prefabricated dowels: a review of compositions, properties, laboratory, and clinical test results. J Prosthodont. 2009;18(6):527-536.

[22] Theodosopoulou JN, Chochlidakis KM. A Systematic review of dowel (post) and core materials and systems. J Prosthodont. 2009;18(6):464-472.

[23] Lee HE, Wang CH, Wu NY, Kuo HL. Stress distribution of prefabricated screw posts. Part I: Post size. Gaoxiong Yi Xue Ke Xue Za Zhi. 1991;7(9):471-475.

[24] Turner CH, Gross MJ. Investigation of hydrostatic pressure changes during cementation of screw-retained posts, and posts with integral cement release channels. J Oral Rehabil. 1983;10(5):421-8.

[25] Farina AP, Cecchin D, Spazzin AO, Pires-de-Souza FP, Mesquita MF. Evaluation of resistance to displacement of mental posts with different lengths. Indian Journal of Dental Research. 2012;2(5):613-616.

[26] Lee HE, Wang CH, Wu NY, Kuo HL. Stress distribution of prefabricated screw posts. Part I: Post size. Gaoxiong Yi Xue Ke Xue Za Zhi. 1991;7(9):471-5.

[27] Kılınç HI, Aslan T, Kılıç K, Er O, Esim E, Yıldııım S. Fracture resistance of teeth with oval canal morphology restored using oval and circular posts. Journal of Oral Science. 2016;58(3):339-345.
[28] Oyar P. The effects of post-core and crown material and luting agents on stress distribution in tooth restorations. The Journal of Prosthetic Dentistry. 2014;112(2):211-219.

[29] Pereira JR, da Rosa RA, So MV, Afonso D, Kuga MC, Honorio HM, do Valles AL, Vdotti HA. Push-out bond strength of fiber posts to root dentin using glass ionomer and resin modified glass ionomer cements. http://dx.doi.org/10.1590/1678-775720130466.

[30] Erbasar CR, Ozdemir E, Hasanoglu Erbasar GN. Effect of various post mterials and resin lutin cements times on microleakage in endotically treated root canals. Journal of Adhesion Science and Technology. 2015;29(16):1651-1662.

[31] Farid F, Mhgoli H, Hosseini A, Chiniforush N. Effect of eugenol-containing and resin endodontic sealers on retention of prefabricated metal posts cemented with zinc phostate and resin cements. Journal of Prosthodontic Research. 2013;57:284-287.

[32] Rezende da Silva N, Rodrigues Aguiar GC, de Paula Rodrigues M, Aredes Bicalho A, Ferreira Soares PB, Veríssimo C, Soares CJ. Effect of Resin Cement Porosity on Retention of Glass-Fiber Posts to Root Dentin: An Experimental and Finite Element Analysis. Brazilian Dental Journal. 2015;26(6): 630-636.

[33] do Vale Pedreira AP, D'Alpino PH, Pereira PN, Chaves SB, Wang L, Hilbert L, Fernanda Cristina Pimentel Garcia FC. Effects of the application techniques of self-adhesve resin cements on the interfacial integrity and bond strength of fiber posts to dentin. http://dx.doi.org/10.1590/1678-775720150600.

[34] Helen-Cot Marcos RM, Ross Kinder G, Alfredo E, Quaranta T, Correr GM, da Cunha LF, Castiglia Gonzaga C. Influence of the Resin Cement Thickness on the Push-Out Bond Strength of Glass Fiber Posts. Brazilian Dental Journal. 2016;27(5):592-598.

Zaakceptowano do edycji: 2018-10-16 Zaakceptowano do publikacji: 2018-12-05

Adres do korespondencji:

Agata Kolenda

Katedra i Klinika Protetyki Stomatologicznej

Uniwersytet Medyczny im. Karola Marcinkowskiego w Poznaniu

ul. Bukowska 70, 60-812 Poznań

tel.: +48662059644

e-mail: agatakolenda@wp.pl 